\title{
A Curious Case of Attempted Hanging in a 7-Year-Old Girl
}

\author{
K. Ravindren Rajith ${ }^{1} \cdot$ Murali Medha $^{2} \cdot$ M. G. Geeta ${ }^{2} \cdot$ Padinharath Krishnakumar $^{1}$ (I)
}

Received: 25 November 2020 / Accepted: 18 March 2021 / Published online: 27 March 2021

(C) Dr. K C Chaudhuri Foundation 2021

To the Editor: We present the case of a 7-y-old girl who tried to hang herself after viewing a television serial. The history was that she tied a knot around her neck using a shawl and tried to hang herself from the window, without any provocation. She was saved by her elder sister who held her up. There was transient unresponsiveness immediately after the event, but she regained consciousness on the way to the hospital. At the time of admission, she was fully conscious and had abrasions on both sides of the neck. Her face was congested, with subconjunctival hemorrhages. There were no neurological deficits or skeletal injury.

Psychological evaluation revealed the following facts. The child lived with her parents and two siblings. She was born of normal delivery and her developmental milestones were normal. There was no family history of mental illness or suicide. She had average academic performance with clinically normal intelligence. There were no features of depression or psychotic illness and no obvious stressors. Her temperament was normal. She had the habit of imitating her teachers. The child had no intention to die and was not fully aware of the meaning of death. She was trying to imitate a female character in a television series who had tried to hang herself.

Media-influenced suicidal behavior in adolescents and adults had been documented in the past [1,2]. The role of visual media in precipitating suicidal behavior in young children with vague or no concept of death has rarely been documented [3, 4]. This case highlights the role of visual media in precipitating self-harming behavior in young children and emphasizes the need for effective guidelines for digital media use by children.

\section{Declarations}

Conflict of Interest None.

Ethical Clearance Written consent from the parent was obtained.

\section{References}

1. Gould MS. Suicide and the media. Ann N Y Acad Sci. 2001;932: 200-21.

2. Schmidtke A, Schaller S. What do we know about media effects on imitation of suicidal behaviour. In: De Leo D, Schmidtke A, Diekstra RFW, editors. Suicide Prevention. Dordrecht: Springer; 1998. https://doi.org/10.1007/0-306-47210-4_13.

3. Geeta MG, Krishnakumar P. Television and suicidal behavior. Indian Pediatr. 2005;42:837-8.

4. Çelik M, Kalenderoğlu A, Almiş H, Turgut M. Copycat suicides without an intention to die after watching tv programs: two cases at five years of age. Noro Psikiyatr Ars. 2016;53:83-4.

Publisher's Note Springer Nature remains neutral with regard to jurisdictional claims in published maps and institutional affiliations.

Padinharath Krishnakumar

krikurp@gmail.com

1 Department of Child and Adolescent Psychiatry, Institute of Mental Health and Neurosciences (IMHANS), Kozhikode, Kerala, India

2 Department of Pediatrics, Government Medical College, Kozhikode, Kerala, India 